\title{
PENGARUH EKSTRAK MINYAK JINTAN HITAM (Nigella sativa) \\ TERHADAP MUKOSA LAMBUNG MENCIT (Mus musculus) \\ YANG DIINDUKSI ETANOL $80 \%$
}

\author{
Syamsu Rijal* \\ *Bagian Histologi Fakultas Kedokteran Universitas Muslim Indonesia
}

\begin{abstract}
Abstrak
Belum adanya penelitian menyeluruh, terpadu, dan terstandarisasi terhadap khasiat Jintan Hitam. Penelitian ini bertujuan Menilai pengaruh pemberian ekstrak minyak Jintan Hitam dosis $0,1 \mathrm{ml} / 20 \mathrm{grBB}, 0,2 \mathrm{ml} / 20 \mathrm{grBB}$, dan $0,3 \mathrm{ml} / 20 \mathrm{grBB}$ yang diberikan selama 4 dan 7 hari terhadap skor ulkus, indeks ulkus, tingkat erosi, jumlah leukosit PMN (Polymophonuclear), dan perubahan morfologi lambung mencit yang diinduksi etanol 80\%. Penelitian ini dilakukan di laboratorium hewan fakultas kedokteran Universitas Hasanuddin pada bulan April - September 2015, dengan desain penelitian eksperimental post test only. Mencit yang digunakan sebanyak 40 ekor, terbagi dalam 8 ekor mencit kelompok kontrol negatif, 8 ekor kelompok kontrol positif, dan kelompok perlakuan pemberian ekstrak minyak Jintan Hitam dosis $0,1 \mathrm{ml} / 20 \mathrm{grBB}, 0,2 \mathrm{ml} / 20 \mathrm{grBB}$, dan $0,3 \mathrm{ml} / 20 \operatorname{grBB}$ masing-masing 8 ekor. Hasil penelitian menunjukkan Pemberian ekstrak minyak Jntan Hitam dosis 0,1 ml/20grBB yang diberikan selama 4 hari, menunjukkan perbedaan yang bermakna antara kelompok kontrol positif dan kelompok perlakuan dengan nilai $\mathrm{p}=0.034(\mathrm{p}<0.05)$ berdasarkan skor ulkus.
\end{abstract} Kata kunci: Ekstrak Minyak Jintan Hitam, skor ulkus, indeks ulkus, tingkat erosi, jumlah leukosit PMN, perubahan morfologi lambung.

\section{PENDAHULUAN}

Ulkus lambung adalah rusaknya lapisan mukosa sampai muskularis mukosa yang berbentuk bulat atau oval $>5 \mathrm{~mm}$ akibat terputusnya kontinuitas integritas mukosa lambung (Taringan \& Akil, 2009; Kumar et al., 2010). Terjadinya ulkus lambung disebabkan oleh ketidakseimbangan antara faktor agresif dan faktor protektif,
Helicobacter pylori (Chai, 2011; Londonkar \& Poddar , 2009), Obat Anti Inflamasi Non Steroid (OAINS), konsumsi alkohol, serta stres (Paguigan et al., 2014; Al et al., 2008; Sultana et a1., 2014).

Prevalensi ulkus lambung dipengaruhi oleh sosial ekonomi, demografi, jenis kelamin, dan usia. Di Amerika Serikat ada 4.000.000 jiwa (12\%) kasus ulkus 
lambung, dengan 500.000 kasus baru (Taringan \& Akil, 2009).

Pengobatan Ulkus Lambung bertujuan untuk mengurangi nyeri, mengobati ulkus, dan mencegah terjadinya ulkus berulang, serta mencegah komplikasi (Al et al., 2008; Paguigan et al. 2014; Taringan \& Akil, 2009). Kondisi tersebut hanya dapat dicapai jika terjadi keseimbangan antara faktor agresif (asam lambung dan pepsin) dan defensif dari mukosa lambung (sekresi mukus,bikarbonat, regenerasi epitel,prostaglandin, dan aliran darah) (Tiuorkey, 2011).

Penggunaan obat-obatan seperti Antasida, H2-reseptor antagonis, Proton Pump Inhibitor, Anti cholinergik, kurang efektif dan menimbulkan banyak komplikasi. Antasida sering menyebabkan Burnett syndrome. Sodium bikarbonat dapat menginduksi alkalosis sistemik (Agus $\mathrm{S}$ et al., 2011). Proton pump inhibitor menyebabkan oxyntic sel mengalami hiperplasia. Ranitidin dan Simetidin dapat menyebabkan agitasi, confusion, lethargy, dan mental depresi. Prostaglandin menyebabkan diare, dan abortus spontan (Sultana et al., 2014). Olehnya itu, perlu dikembangkan usaha untuk menemukan pengobatan yang efektif dan bersumber dari alam (Adinortey et al., 2013; Hasan et al., 2014; Agus S et al., 2011).
Nigella sativa sama efektifnya dengan Simetidin dalam menyembuhkan ulkus lambung, dan dapat diberikan secara bersama-sama dalam praktik sehari-hari (Khalil et al., 2010).

Penelitian ini bertujuan untuk menilai pengaruh ekstrak minyak Jintan Hitam dosis 0,1 $\mathrm{ml} / 20 \quad \mathrm{grBB} / \mathrm{hari}, \quad 0,2 \mathrm{ml} / 20 \mathrm{grBB}$, $0,3 \mathrm{ml} / 20 \mathrm{grBB}$ yang diberikan selama 4 dan 7 hari terhadap skor ulkus, indeks ulkus, tingkat erosi, jumlah leukosit PMN (Polymophonuclear), dan perubahan morfologi lambung mencit yang diinduksi etanol $80 \%$.

\section{BAHAN DAN METODE}

\section{Lokasi dan Rancangan Penelitian}

Penelitian dilakukan di Laboratorium Hewan Fakultas Kedokteran Universitas Hasanuddin, laboratorium Patologi Anatomi Fakultas kedokteran Universitas Hasanuddin, dan laboratorium Fakultas Farmasi Universitas Muslim Indonesia pada bulan April - September 2015. Penelitian ini merupakan penelitian eksperimental Post Test only Control Group Design, dengan menggunakan mencit (Mus musculus) sebagai subyek penelitian.

\section{Populasi dan Sampel Penelitian}

Populasi dan sampel penelitian merupakan hewan yang tergolong mencit (Mus musculus) yang didapatkan dari laboratorium Hewan Fakultas Kedokteran 
Hewan Universitas Hasanuddin Makassar. Sampel penelitian adalah keseluruhan populasi terjangkau yang memenuhi kriteria inklusi. Penelitian dibagi dalam lima kelompok. Jumlah mencit dihitung menggunakan rumus federer, sebanyak 40 ekor mencit.

\section{Metode Pengumpulan Data}

Pada penelitian ini, jumlah sampel yang digunakan sebanyak 40 mencit, terbagi dalam 5 kelompok, yaitu; Kelompok Kontrol negatif (K-), terdiri dari 8 ekor mencit tanpa perlakuan. Kelompok Kontrol positif $(\mathrm{K}+)$, terdiri dari 8 ekor mencit. Tiga ekor mencit yang diinduksi etanol $80 \% \quad 0,1 \mathrm{ml} / 20 \mathrm{grBB}$ selama dua hari, kemudian dilanjutkan dengan pemberian pakan standar selama 4 hari, dipuasakan 24 jam dengan akses air minum bebas, kemudian euthanasia hari ke-5. Lima ekor mencit yang diinduksi etanol 80\% 0,1ml/20grBB selama dua hari, kemudian dilanjutkan dengan pemberian pakan standar selama 7 hari, dipuasakan 24 jam dengan akses air minum bebas, kemudian dilakukana euthanasia hari ke-8. Kelompok perlakuan satu (P1), perlakuan dua (P2), perlakuan tiga (P3) masing-masing terdiri dari 8 ekor mencit. Tiga ekor mencit untuk masingmasing kelompok P1, P2, P3 yang diinduksi etanol $80 \% \quad 0,1 \mathrm{ml} / 20$ grBB selama dua hari, kemudian dilanjutkan dengan pemberian ekstrak minyak Jintan Hitam dosis 0,1 $\mathrm{ml} / 20 \mathrm{grBB}, 0,2 \mathrm{ml} / 20 \mathrm{grBB}, 0,3 \mathrm{ml} / 20 \mathrm{grBB}$ satu kali sehari dan pakan standar selama 4 hari, dipuasakan 24 jam dengan akses air minum bebas, kemudian dilakukan euthanasia hari ke-5. Lima ekor mencit untuk masing-masing kelompok P1, P2, P3, yang diinduksi etanol $80 \%$ 0,1ml/20grBB selama dua hari, kemudian dilanjutkan dengan pemberian ekstrak minyak Jintan Hitam dosis $0,1 \mathrm{ml} / 20 \operatorname{grBB}, 2 \mathrm{ml} / 20 \mathrm{grBB}, 0,3$ ml/20grBB satu kali sehari dan pakan standar selama 7 hari, dipuasakan 24 jam dengan akses air minum bebas, kemudian dilakukan euthanasia hari ke-8.

\section{Analisis data}

Analisis univariat: digunakan untuk mendeskripsikan karakteristik data yang diperoleh berupa distribusi frekuensi, ratarata, yang disajikan dalam bentuk tabel. Analisis bivariat menggunakan pengujian statistik parametrik berupa : Uji $\mathrm{X}^{2}$ : untuk data sampel yang tidak berpasangan yang datanya berskala nominal dikotom. Pada penelitian ini digunakan untuk menilai hubungan antara kelompok kontrol negatif (K-), kelompok kontrol positif $(\mathrm{K}+)$ yang hanya diberikan etanol $80 \%$ dan kelompok perlakuan P1,P2,P3, yang diberikan etanol $80 \%$ kemudian dilanjutkan dengan pemberian ekstrak minyak Jintan Hitam dosis 0,1 $\mathrm{ml} / 20 \mathrm{grBB}, \quad 0,2 \mathrm{ml} / \mathrm{grBB}$, dan 0,3 ml/grBB selama 4 dan 7 hari. Uji MannWhitney : untuk sampel yang tidak berpasangan yang datanya berskala ordinal. 
Pada penelitian ini digunakan untuk menilai hubungan antara kelompok kontrol negatif (K-), kelompok kontrol positif $(\mathrm{K}+)$ yang hanya diberikan etanol $80 \%$ dan kelompok perlakuan P1,P2,P3, yang diberikan etanol $80 \%$ kemudian dilanjutkan dengan pemberian ekstrak minyak Jintan Hitam dosis $0,1 \mathrm{ml} / 20 \mathrm{grBB}, \quad 0,2 \mathrm{ml} / \mathrm{grBB}$, dan 0,3 $\mathrm{ml} / \mathrm{grBB}$ selama 4 dan 7 hari. Uji t test: digunakan untuk membandingkan dua kelompok yang tidak berpasangan menggunakan mean atau rerata yang yang berskala numerik. Pada penelitian ini digunakan untuk menilai hubungan antara kelompok kontrol negatif (K-), kelompok kontrol positif $(\mathrm{K}+)$ yang hanya diberikan etanol $80 \%$ dan kelompok perlakuan $\mathrm{P} 1, \mathrm{P} 2, \mathrm{P} 3$, yang diberikan etanol $80 \%$ kemudian dilanjutkan dengan pemberian ekstrak minyak Jintan Hitam dosis $0,1 \mathrm{ml} / 20$ grBB, 0,2 ml/grBB, dan 0,3 ml/grBB selama 4 dan 7 hari. Penilaian uji hipotesis, tidak bermakna bila $p>0,05$, bermakna bila $p<0,05$.

\section{HASIL}

\section{Karakteristik Sampel Penelitian}

Tabel 1. Karakteristik umum Sampel setelah Perlakuan $(n=40)$

\begin{tabular}{lll}
\hline \multicolumn{1}{c}{ Karakteristik } & Nilai \\
\hline Skor Ulkus & Rerata \pm SB & $0.45 \pm 0.85$ \\
& Median & 0 \\
& Maksimum-minimum & $0-3$ \\
Indeks Ulkus & Rerata \pm SB & $0.12 \pm 0.22$ \\
& Median & 0 \\
Jumlah leukosit PMN (/LPB) & Maksimum-minimum & $0-0.67$ \\
& Rerata \pm SB & $10.93 \pm 13.29$ \\
Tingkat erosi (n(\%)) & Median & 7.5 \\
& Maksimum-minimum & $0-53$ \\
& Tidak ada lesi & $8(20)$ \\
& Ringan & $22(55)$ \\
& Sedang & $8(20)$ \\
& Besar & $2(5)$ \\
& Ada & $19(47.5)$ \\
& Tidak ada & $21(52.5)$
\end{tabular}

Keterangan : $\mathrm{SB}=$ simpang baku, $\mathrm{PMN}=$ polimorfonuklear, LPB = lapangan pandang besar 
Berdasarkan tabel 1, skor ulkus rerata $\pm \mathrm{SB}$ sedangkan erosi berat hanya 2 ekor mencit $0.45 \pm 0.85$, median 0 . Indeks ulkus rerata $\pm \quad(5 \%)$. Terjadinya perubahan morfologi yang SB $0.12 \pm 0.22$, median 0 . Tingkat erosi terjadi 19 mencit $(47,5 \%)$, dan yang tidak ringan yang terbanyak 22 ekor mencit ditemukan perubahan morfologi 21 mencit (55\%), tidak ada lesi dan erosi sedang (52,5\%).

masing-masing 8 ekor mencit (20 \%),

\section{Analisis Bivariat}

Tabel 2. Perbandingan skor ulkus antara hari ke-4 dan hari ke-7 pada Kelompok Kontrol dan kelompok Perlakuan

\begin{tabular}{|c|c|c|c|c|c|c|c|}
\hline Kelompok & $\begin{array}{l}\text { Lama } \\
\text { Perlakuan }\end{array}$ & $\mathrm{n}$ & $\begin{array}{l}\text { Rerata } \pm \\
\text { SB }\end{array}$ & Median & Minimum & Maksimum & Nilai $p$ \\
\hline \multirow{2}{*}{$\begin{array}{l}\text { Kontrol } \\
\text { negatif }\end{array}$} & Hari ke-4 & 3 & 0 & 0 & 0 & 0 & \\
\hline & Hari ke-7 & 5 & 0 & 0 & 0 & 0 & \\
\hline \multirow{2}{*}{$\begin{array}{l}\text { Kontrol } \\
\text { Positif }\end{array}$} & Hari ke-4 & 3 & 2 & 2 & 2 & 2 & \multirow[b]{2}{*}{$1.000^{*}$} \\
\hline & Hari ke-7 & 5 & $\begin{array}{l}1.80 \pm \\
1.09\end{array}$ & 2 & 0 & 3 & \\
\hline \multirow[t]{2}{*}{ Jintan $0.1 \mathrm{ml}$} & Hari ke-4 & 3 & $\begin{array}{l}0.33 \pm \\
0.58\end{array}$ & 0 & 0 & 1 & \multirow[t]{2}{*}{$0.197^{*}$} \\
\hline & Hari ke-7 & 5 & 0 & 0 & 0 & 0 & \\
\hline \multirow[t]{2}{*}{ Jintan $0.2 \mathrm{ml}$} & Hari ke-4 & 3 & $\begin{array}{l}0.33 \pm \\
0.58\end{array}$ & 0 & 0 & 1 & \multirow[t]{2}{*}{$0.197^{*}$} \\
\hline & Hari ke-7 & 5 & 0 & 0 & 0 & 0 & \\
\hline \multirow[t]{2}{*}{ Jintan $0.3 \mathrm{ml}$} & Hari ke-4 & 3 & $\begin{array}{l}21.67 \pm \\
3.22\end{array}$ & 23 & 18 & 24 & \multirow[t]{2}{*}{$0.197 *$} \\
\hline & Hari ke-7 & 5 & 0 & 0 & 0 & 0 & \\
\hline
\end{tabular}

Keterangan: * Uji Mann-Whitney, ** Uji t

Hari ke-4 :

1. $\mathrm{K}-\mathrm{vs} \mathrm{K}+=0.002$

2. $\mathrm{K}-\mathrm{vs} \mathrm{P} 1=0.317$

3. $\mathrm{K}-\mathrm{vs} \mathrm{P} 2=0.317$

4. $\mathrm{K}-\mathrm{vs} \mathrm{P} 3=0.317$

5. $\mathrm{K}+$ vs $\mathrm{P} 1=0.034$

6. $\mathrm{K}+\mathrm{vs} \mathrm{P} 2=0.034$
7. $\mathrm{K}+$ vs $\mathrm{P} 3=0.034$

8. $\mathrm{P} 1$ vs $\mathrm{P} 2=1.000$

9. $\mathrm{P} 1$ vs $\mathrm{P} 3=1.000$

10. $\mathrm{P} 2$ vs $\mathrm{P} 3=1.000$

Hari ke-7 :

1. $\mathrm{K}-\mathrm{vs} \mathrm{K}+=0.006^{* *}(\mathrm{Uji} \mathrm{t})$ 
2. $\mathrm{K}-\mathrm{vs} \mathrm{P} 1=1.000^{*}$

3. $\mathrm{K}$ - vs $\mathrm{P} 2=1.000 *$

4. $\mathrm{K}-\mathrm{vs} \mathrm{P} 3=1.000^{*}$

5. $\mathrm{K}+$ vs $\mathrm{P} 1=0.006^{*}$

6. $\mathrm{K}+\mathrm{vs} \mathrm{P} 2=0.006^{*}$

7. $\mathrm{K}+$ vs $\mathrm{P} 3=0.006^{*}$

8. $\mathrm{P} 1$ vs $\mathrm{P} 2=1.000^{*}$

9. $\mathrm{P} 1$ vs $\mathrm{P} 3=1.000^{*}$

10. $\mathrm{P} 2$ vs $\mathrm{P} 3=1.000^{*}$

Berdasarkan data tabel 2, perlakuan hari ke4 kelompok kontrol negatif nilai median 0 , dan kelompok kontrol positif nilai median 2 . Hasil uji Mann-Whitney diperoleh $\mathrm{p}=0,002$ $(<0,05)$. Hal ini menunjukkan perbedaan yang bermakna. Kelompok perlakuan P1, P2, P3, masing-masing nilai median 0 , bila dibandingkan dengan kelompok kontrol positif diperoleh perbedaan yang bermakna, dengan nilai $\mathrm{p}=0,034(<0,005)$. Pada perlakuan hari ke-7 pada kelompok kontrol negatif nilai rerata 0 , dan kelompok kontrol positif nilai rerata $1,8 \pm 1,1$. Hasil uji $t$ test diperoleh $\mathrm{p}=0,006(<0,05)$. Hal ini menunjukkan perbedaan yang bermakna antara kelompok kontrol negatif dan kelompok kontrol positif. Kelompok perlakuan P1, P2, P3, masing-masing nilai median 0 , bila dibandingkan dengan kelompok kontrol positif didapatkan perbedaan yang bermakna, dengan nilai $\mathrm{p}=$ $0,006(<0,005)$.

\section{PEMBAHASAN}

Penelitian ini menunjukkan bahwa kelompok kontrol positif dapat dijadikan pembanding dengan kelompok P1, P2, P3. Penggunaan ekstrak minyak Jintan Hitam pada dosis $0,1 \mathrm{ml} / 20 \mathrm{grBB}$ dapat digunakan sebagai dosis terapi pada pemberian hari ke-4, bila dibandingkan dengan pemberian hari ke7. Dengan menggunakan uji Mann-Whitney pada perbandingan skor ulkus antara hari ke4 dan hari ke-7 terlihat bahwa pada kelompok kontrol positif diperoleh nilai $p=1,000 \quad(p>0,05)$, kelompok P1 diperoleh nilai $p=0,197 \quad(p>0,05), \quad$ kelompok $\quad P 2$ diperoleh nilai $p=0,197 \quad(p>0,05, \quad$ dan kelompok P3 diperoleh nilai $\mathrm{p}=0,197$ $(\mathrm{p}>0,05)$. Hal ini menunjukkan tidak ada perbedaan yang bermakna pada semua kelompok.

Pada dosis minimal 0,1 ml/20grBB sebagai dosis terapi, pada pemberian selama 4 hari. Hal ini didukung penelitian yang dilakukan oleh Khalil Javed dan kawankawan yang menunjukkan perbaikan ulkus lambung dan penurunan indeks lambung pada pemberian ekstrak Jintan (Khalil et al., 2010). Demikian juga penelitian yang dilakuan Hasan dan kawan-kawan pada pemberian ekstrak jintan dosis $200 \mathrm{mg} / \mathrm{kg}$ dan $400 \mathrm{mg} / \mathrm{kg}$ peroral selama 5 hari pada tikus menunjukkan penurunan indeks ulkus dan hanya terjadi distrosi ringan pada mukosa lambung (Hasan et al., 2014). 
Penelitian yang dilakukan oleh Mohua dan kawan-kawan bahwa, pemberian Jintan Hitam $500 \mathrm{mg} / \mathrm{Kg}$ pada tikus selama 5 hari dapat menurunkan Indeks Ulkus dibandingkan dengan Ranitidin dosis 20 $\mathrm{mg} / \mathrm{kg}$. Hal ini disebabkan karena komponen Jintan Hitam yakni Thymoquinone bersifat cytoprotective yang tidak hanya mereduksi indeks ulkus, tapi juga menghambat sekresi asam lambung dan tingkat keasamannya (Mohua et al., 2013).

Menurut Tarnawski \& Ahluwalia (2012), proses terjadi inisiasi atau penyembuhan ulkus lambung dimulai pada hari 3 setelah induksi ulserogenik, dalam hal ini etanol $80 \%$. Tahapan pertama; adalah reepitelisasi, kedua; pembentukan formasi, migrasi dan rekonstruksi kelenjar, ketiga; angiogenesis, keempat; remodeling. Penyembuhan ulkus lambung pada perubahan yang terjadi di mukosa lambung seperti kongesti, hemoragik, edema, nekrosis, tingkat inflamasi,erosi,ulserasi, dysplastic change (Al et al., 2008).

Alkohol absolut diserap dengan cepat oleh lambung dan usus yang menginduksi terjadinya cidera vaskuler endotel dari mukosa lambung, edema, kongestif, bercak perdarahan, perdarahan fokal, nekrosis, dan bisa terjadi ulkus yang dalam. Hal ini disebabkan struktur sel Principal dan sel Parietal lambung yang mengandung banyak mitokondria, menjadi bengkak dan berkurang, disebabkan karena organel mitokondria mudah dirusak oleh etanol (Manzo\& Saavedra, 2010).

Dosis yang dipakai untuk menurunkan jumlah leukosit PMN pada pemberian ekstrak minyak Jintan hitam adalah $0,2 \mathrm{ml} / 20 \mathrm{grBB}$ namun belum efektif untuk menurunkan jumlah leukosit PMN. Hal serupa juga didapatkan oleh peneliti Bashir dan kawan-kawan dengan membandingkan kelompok kontrol, kelompok pemberian Jintan Hitam dan sodium diklorofenak. Tidak ada perbedaan yang signifikan antara ketiga kelompok tersebut, baik dilihat dari Total Leukocyte Count dan Differential Leokocyte Count (Bashir et al., 2015). Hal yang berbeda dilaporkan oleh Magdy dan kawan-kawan bawah Thymoquinone mampu mereduksi invasi neutrofil dengan mengamati aktifitas MPO (Myeloperoxidase) yang juga menurun pada model gastric injury (Magdy et al., 2012).

$\begin{array}{rcc} & \text { Penyembuhan ulkus lambung di } \\ \text { klinik didasarkan pada pemeriksaan }\end{array}$ endoskopi visual, sementara dalam penelitian didasarkan pada evaluasi makroskopik dan pengukuran ulkus lambung. Namun pada pemeriksaan mikroskopik masih tampak dilatasi kelenjar lambung, jaringan ikat yang banyak, mikrovaskuler yang meningkat, serta pemulihan saraf sensorik. Parameter Ini dapat dijadikan dasar dalam menilai kualitas 
pemyembuhan ulkus lambung (Tarnawski \& Ahluwalia 2012).

\section{KESIMPULAN DAN SARAN}

Pemberian ekstrak minyak Jntan Hitam dosis $0,1 \mathrm{ml} / 20 \mathrm{grBB}$ yang diberikan selama 4 hari, sebagai dosis efektif berdasarkan skor ulkus.

Disarankan perlu dilakukan penelitian lanjutan untuk mengamati perubahan mukosa lambung pada hari ke-1, hari ke-2, hari ke-3, hari ke-5, dan hari ke-6, berdasarkan skor ulkus, indeks ulkus, tingkat erosi, jumlah leukosit PMN. Perlu dilakukan penelitian lanjutan untuk melihat efek samping ekstrak minyak Jintan Hitam pada binatang percobaan. Perlu dilakukan uji klinik untuk melihat pengaruh pemberian ekstrak minyak Jintan Hitam.

\section{DAFTAR PUSTAKA}

AdinorteyM. B. et al. (2013). In Vivo Models Used for Evaluation of Potential Antigastroduodenal Ulcer Agents. , 2013, pp.1-11. Available at: http://dx.doi.org.

Agus S., Setyo T. \& Perwira N.H. (2011). The Effect of Honey Administration on Gastrohistopathological Image Study In Male White Wistar Rat Induced With Indomethacin. Sainsmedika, 3, pp.41-47. Available at: sainsmedika.fkunissula.ac.id.
Al I.A. et al. (2008). Gastroprotective Effect of an Aqueous Suspension of Black Cumin Nigella sativa on Necrotizing Agents-Induced Gastric Injury in Experimental Animals. The Saudi Journal of Gastroenterology, 14(3), pp.128-134. Available at: www.saudijgastro.com.

Bashir M.U., Qureshi H.J. \& Saleem T. (2015). Comparison of AntiInflammatory Activity of Nigella Sativa and Diclofenac Sodium in Albino Rats. Journal of Ayub Medical College, Abbottabad: JAMC, 27(3), pp.523-526. Chai J. (2011). Edited by Jianyuan Chai Fist. Chai Jianyuan, ed., Croatia: InTech Janeza Trdine 9, 51000 Rijeka, Croatia. Available at: www.intechopen.com/orders@intechwe b.org.

Hasan M.N. et al. (2014). PROTECTIVE EFFECT OF NIGELLA SATIVA AGAINST ASPIRIN INDUCED GASTRIC DAMAGE IN RATS. International Journal of Pharmacy and Pharmaceutical science, 6(5), pp.275278. Available at: hasan.nazar@gmail.com Khalil J., Akhter S., Bhatti S.A. et al. (2010). GASTRIC ULCER HEALING EFFECTS OF NIGELLA SATIVA; A COMPARATIVE EXPERIMENTAL 
STUDY WITH CIMETIDINE.

/Biomedica, 26, pp.61-65.

Khalil, J., Akhter, S., Bhatti, S. a, et al., 2010.

Gastric Ulcer Healing Effects of Nigella

Sativa ; a Comparative Experimental

Study With Cimetidine. , 26, pp.61-65.

Kumar V. et al. (2010). Robbins and Cotran

Pathologic Basis of Disease 8th ed.,

Cina: Sanders Elsevier.

Londonkar R.L. \& Poddar P. V. (2009).

Studies on activity of various extracts of

Mentha arvensis Linn against drug

induced gastric ulcer in mammals. , 1(1),

pp.82-88. Available at:

www.wjgnet.com/1948-5204office.

Magdy M.A., Hanan E.A. \& Nabila E.M.

(2012). Thymoquinone: Novel

gastroprotective mechanisms. European

Journal of Pharmacology, 697(October

2012), pp.126-131.

Manzo A. S. \& Saavedra M.A. (2010).

Cellular and mitochondrial effects of

alcohol consumption. International

Journal of Environmental Research and

Public Health, 7, pp.4281-4304.

Mohamed A. et al. (2010). The Protective of

Nigella Sativa (NS), Nicotinic Acid

(NA), end Zinc sulphate (ZNS) on

Alcohol Induced gGastric Lesions in

Albino Rats. J Punjab Acad Forensic

Med Toxicol, 2, pp.78-86.

Mohua S. et al. (2013). Research Article

Evaluation of Anti-Ulcer Activity of
Aqueous Extract of Black Cumin Seeds

( Nigella Sativa L ) on Experimental

Albino Rats. , 3(1), pp.25-28.

Paguigan N.D., Castillo D.H.B. \& Chichioco

H.C.L. (2014). Anti Ulcer Activity of

Leguminosae Plants. , (1), pp.64-68.

Tarnawski \& Ahluwalia. (2012). Molecular

Mechanisms of Epithelial Regeneration and Neovascularization During Healing of Gastric and Esophageal Ulcers.

Current Medicinal Chemistry, 19(1), pp.16-27. Available at:

http://www.eurekaselect.com/openurl/co ntent.php?genre $=$ article \&issn $=0929$ $8673 \&$ volume $=19 \&$ issue $=1 \&$ spage $=16$.

Sultana S. et al. (2014). Complementary and Alternative Approaches to Treat Peptic Ulcer. International Research of Pharmacy, 5(5), pp.353-359. Available at: www.irjponline.com.

Taringan \& Akil (2009). Tukak Gaster dan Tukak Duodenum. In S. A. W et al., eds. Buku Ajar Ilmu Penyakit Dalam. Jakarta: InternaPublishing, pp. 513-528. Available at: email:pipfkui@yahoo.com. Tiuorkey M.J. (2011). Gastric Ulcer's Diseases Pathogenesis, Complications and Strategies for Prevention. webmedcentral, pp.1-24. Available at: from http://www.webmedcentral.com. 
